any attempt to summarise it must meet with failure : every aspect of the subject is dealt with in all its bearings, and there is scarcely a redundant word. The chapter on the aim and function of geography is particularly illuminating. Stress is laid on the fact that school geography must be the geography of geographers: not the mere learning of geographical data and results, but a training in the geographer's characteristic methods and principles of interpretation, and an assimilation of his characteristic point of view. This, we consider, is a most important statement, and postulates a trained geographer for the success of any geographical scheme.

Proceeding, the Report deals with the stages of school life, and outlines the principles which should guide in the formation of a syllabus of geographical instruction in secondary schools : a detailed syllabus for each year is appended. Stress is laid on the necessity of proceeding psychologically with young children and of adopting a logical order only as riper years are gradually reached. An outline scheme for each stage, including the advanced course, is given, and apart from its merits as a scheme it possesses special value for the teacher because the underlying aim of each step is made abundantly clear. Great importance is attached throughout to the value of direct observational work and to the construction and interpretation of maps and charts. "One important value of geography in education is the opportunity it gives to express thought in diagram and sketch no less than in words." This sentence should be constantly in the mind of every geography teacher. A highly controversial dictum is that formal lessons in physical geography should not precede the advanced course : incidental teaching of most subjects is apt to be disjointed and incoherent, and the experience of many examiners at matriculation proves that geography is no exception to the rule.

The suggestions for a scheme of study in the advanced courses are excellent. Emphasis is laid on the economic conditions of the modern world, and it is suggested that a small area be selected for comprehensive analysis and synthesis. Correlation of the subsidiary subjects is of course taken for granted.

The chapter on the relation of geography to science and history cannot fail to impress upon the most uninformed reader what a tremendous range of knowledge, not only of topographical facts, but of such allied subjects as physics, geology, botany, biology, history, and economics, is demanded of the geography teacher called upon to carry out such a modern geography course. It is pointed out that it is not his duty to teach these subjects; nevertheless, to correlate them he must know them. The Report proceeds to summarise the facilities offered at the universities for the training of geography teachers. Practically all the universities have established honours schools of geography-mostly in the Faculty of Arts - and there is general agreement that the subject of study should include geology, history, and political economy at least to intermediate standard. The number of trained geographers leaving the universities is steadily increasing, and "the result," to quote the Report, " undoubtedly will be not only a more thorough and scientific study of the subject, but a general increase of accurate knowledge of the Empire and the rest of the world, which will affect the everyday life of the community through its economic and political relationships with other countries."

J. Martin.

\title{
Transport and its Indebtedness to Science.
}

$\mathrm{I}$ the Engineering Section of the British Association at Liverpool, one whole morning was devoted to the subject of transport, the other sessions being occupied by papers-many of great intereston very diverse branches of engineering. The president of the Section, Sir Henry Fowler, was chief mechanical engineer of the Midland Railway, and he took as the subject of his address "Transport and its Indebtedness to Science." extracts from which were published in NatURE of September 29, p. 474. He was followed by Mr. A. E. Berriman, the chief engineer of the Daimler Co.; Col. O'Brien, the electrical engineer of the L.M.S. Railway; Major-General Sir Sefton Brancker, of the Air Force; and Mr. A. T. Wall, of Messrs. Wall, Maas and Co., naval architects, of Liverpool.

Each speaker dealt with the branch of the subject with which he was specially identified. As the president pointed out, there is probably no city in the world more dependent on transport than Liverpool, and no city which has done such pioneer service in its development. Whether one considers canals, steam railways, electric railways, or motor traffic, one finds that Liverpool was in the forefront of development, and it was a happy thought of the president, a nonacademic engineer, engaged in practice, to take as his thesis that progress in all means of transport has been based upon scientific investigation, to predict that this will be even more marked in the future, to insist on the interdependence of science and engineering, and the necessity for the terms scientific and practical being synonymous. In concluding his address Sir Henry said that " one would like to feel that the meetings of the British Association were more generally used as the occasion on which the scientist and the engineer would meet in larger numbers."
Mr. Berriman gave a very valuable review of the position of road transport. $\mathrm{He}$ was somewhat scathing in his criticism of the railway companies' lack of faith in the railway principle, as shown by their proposal to operate their awn road vehicles for through traffic. He maintained that, since the tractive effort on rails is only $5 \mathrm{lb}$. per ton against $60 \mathrm{lb}$. per ton on average roads, it is technically a sheer waste of energy to transport by road between distant points that are rail-connected. Mr. Berriman also dealt with the question of traffic regulation, and maintained that the warning signs on roads have been put up on a wrong principle and are consequently largely disregarded; in his view, every crossing should have a primary and a secondary stream of traffic, the former having priority and not being expected to slow down; drivers on the secondary roads would be warned to go dead slow on approaching a crossing.

Col. O'Brien's paper, as was to be expected, dealt largely with the question of electrification, which is really an economic one; there are no engineering difficulties. "A very slight lowering of rates of interest and in the price of the material required for such electrification is likely to produce a very considerable development in future." "There is no doubt that the electrification of any main line containing gradients of I in 300 or greater and averaging over 2 trains per hour in either direction would at least involve no loss of any kind to the company, while the indirect advantage to both the railway company and the electrical industry of the country would be very large."

Sir Sefton Brancker's breezy optimism with regard to aerial transport caused some amusement. He was fortunate in delivering his paper before the news came

NO. 2822 , VOL. I I 2$]$ 
through of the London-Manchester air-mail disaster, which occurred on the same day, more especially as he emphasised the safety, comfort, and exhilaration of flying. Under present conditions, he stated, the cost per passenger-mile could not be reduced below $8 \frac{1}{2}$ pence, whilst the highest fare obtainable was 6 pence per mile, leaving $2 \frac{1}{2}$ pence to be covered by subsidy. Freight costs per ton-mile he placed at $3 s$. $6 d$. to $5^{s}$. The only difficulty in the way of development, beyond the economic one, is the difficulty and danger of flying under conditions of poor visibility. The economic range for airships is more than rooo miles, whilst that of aeroplanes is rarely more than 300 miles, hence the two are complementary and should develop together.

In dealing with sea transport, Mr. Wall emphasised the need for scientific research, especially in metallurgy, but he stated that a very hopeful sign for future progress is to be found in the increasing number of scientific experiments on a large scale carried out by shipbuilders and engineers and sometimes by shipowners. "Experience may, and often does, precede the scientific treatment, but progress is much more rapid when science is used to guide experience."

\section{The Future of the Imperial Institute.}

A WHITE Paper (Cmd. I997), issued on November 22, contains the report of the Committee appointed by the Secretary of State for the Colonies to inquire into the affairs of the Imperial Institute, consequent upon financial difficulties, and also the resolutions passed by the Imperial Economic Conference on considering that report. An article commenting upon the recently published report on the work of the Institute appeared in NATURE of November Io, p. 677 .

The Committee considers that the collection and dissemination of information in regard to raw materials is the most important work carried out by the Imperial Institute at the present time. It recommends that the Imperial Institute should continue to function at South Kensington as a clearing-house of intelligence and information, equipped with laboratories for the preliminary analysis and investigation of raw materials, and maintaining sample rooms illustrative of Empire raw materials. The collections in the Public Exhibition Galleries, although recognised as possessing educational value, are not regarded as essential to the future work of the Institute, and it is recommended that the collections be discontinued, though the Committee is by no means unanimous on this point, as is shown by a note appended to the report. It is proposed, however, that a representative selection of Empire products should be made for the purpose of a travelling exhibition of an educational character, and that the organisation of travelling exhibitions of the staple products of the Colonies and Protectorates in appropriate trade centres should be considered.

The Committee proposes reforms in the management of the Institute, suggesting that it should be made responsible to the Department of Overseas Trade. After the completion of these reforms, the Committee recommends the amalgamation of the Imperial Mineral Resources Bureau and the Imperial Institute. The annual expenditure of the reformed Institute (including the Imperial Mineral Resources Bureau) is estimated at about $40,000 l$., to be provided on a contributory basis. Failing the provision of this sum, which is regarded as a condition precedent to the Committee's recommendations, an alternative scheme is proposed to retain the essential functions of the present Institute, i.e. of an intelligence and information bureau.

The Committee expresses appreciation of the valuable services rendered by the Director, Prof. W. R. Dunstan, F.R.S., to the Institute and to the Empire during the long period of his connexion with the Institute, and pays a tribute to the work of the technical staff. Prof. Dunstan was appointed Director in 1903, when he had already been for eight years concerned with the work of the Institute.

The report was submitted by H.M. Government to the Imperial Economic Conference, with the proposal that the main scheme of the Committee should be adopted and the necessary funds guaranteed for a term of years. On the recommendation of a Committee appointed by the Conference, under the chairmanship of Lord Salisbury, the main scheme was adopted, subject to certain modifications not affecting the principles involved.

In the Times of November 23 it was announced that, in view of the changes in the constitution of the Imperial Institute which have been decided upon, Prof. W. R. Dunstan will resign the directorship of the Institute next month.

\section{University and Educational Intelligence.}

Birmingham.-Mr. Henry Barber, of Culham Court, Henley-on-Thames, who was formerly a solicitor in Birmingham, has given $20,000 l$. for the endowment of a chair of law in the University.

Mr. H. P. Dean has been appointed assistant lecturer in mechanical engineering, and $\mathrm{Mr}$. M. C. Johnson demonstrator in physics.

It is hoped that Prof. F. C. Lea, who has recently resigned the chair of civil engineering on being appointed head of the Engineering Department of the University of Sheffield, will continue to discharge the duties attaching to the chair for the rest of the current session.

CAMBRIDGE.-The degree of Master of Arts, honoris causa, is to be conferred upon Mr. J. B. Buxton, professor of animal pathology.

Prof. T. B. Wood has been reappointed by the University as a Member of the Council of the National Institute of Agricultural Botany.

The Frazer lecture is to be delivered by the Rev. John Roscoe on "Immigrants and their Influence in the Lake Region of Central Africa."

A syndicate has been appointed to obtain plans and estimates for extending the School of Agriculture and constructing a building for the Animal Diseases Institute.

Glasgow.-Prof. W. J. Goudie, James Watt professor of the theory and practice of heat engines, has given 5ool. to found an "Agnes Rhind " bursary in memory of his mother, for a third-year student of mechanical engineering who has the best class-record in his subject.

Mr. A. Henderson Bishop and his son have offered to the University, for the new Zoological Museum, the great collection of Coleoptera and Lepidoptera made by his late father, Thomas G. Bishop, of Dalmore, Helensburgh. The collection is contained in 18 cabinets enclosing 700 separate boxes, and numbers some thirty or forty thousand specimens. All are beautifully mounted, labelled, systematically arranged, and in perfect condition. The University has had no difficulty in accepting the splendid gift, with the condition that it shall be accessible for consultation by qualified entomologists, whether they belong to the University or not. 